\title{
Memória de Futuro ou depois da curva de estrada, o movimento antimilitarista ibérico entre 1980 e 1999
}

\author{
Memory of the Future or after the road curve, the Iberian anti- \\ military movement between 1980 and 1999
}

\author{
Enviado em: 30/09/2020 \\ Aceito em: 05/12/2021 \\ João Carlos Louçã ${ }^{1}$
}

\section{Resumo}

O trabalho de terreno com os pés assentes no presente etnográfico que interroga invariavelmente o passado e os seus usos para vislumbrar o futuro, comporta com frequência momentos de espanto. $\mathrm{Na}$ antropologia que olha o tempo que está para vir como um caleidoscópio de possibilidades em aberto, essas ocasiões sugerem conexões entre mundos que se cruzam, que por vezes divergem e podem voltar a encontrar-se, traçando sempre caminhos inesperados para a investigação projetada. Em comunidades que procuram na complexidade do presente a simplicidade de formas de vida desejadas, que concretizam utopias nas formas de produzir, trocar, educar ou decidir entre si, que transformam precariedade em possibilidade continuada, alguns desses momentos emergiram com estrondo. Nos Pirinéus do Alto Aragão vivem pessoas que desde os anos 70 do século passado influenciaram decisivamente o movimento antimilitarista em Portugal no final da década de 80. Este movimento contestou o serviço militar obrigatório, a pertençaà Nato e a lógica da guerra fria que espalhava mísseis pela Europa num braço de ferro que ninguém podia ganhar, envolveu uma geração urbana que da revolução de 1974 vivia o tempo de normalização e do discurso que repudiava os "excessos da revolução". Para os jovens em torno do Movimento Tropa Não português, o exemplo espanhol da insubmissão ao serviço militar, da objeção de consciência que fez milhares de prisões no Estado vizinho mobilizando amplos setores, foi inspiração e cumplicidade, motor de arranque e argumento. Mais de trinta anos depois, estes encontros fazem das memórias de quem investiga material fundamental para acompanhar aquilo que se procura entender no tempo longo de uma vida ou no de movimentos sociais que ganham outras causas. A melancolia que Enzo Traverso (2019) aponta como característica para a esquerda do século XXI por não ter novas esperanças coletivas no horizonte, poderá estar a ser contrariada nos exemplos de lutas que se inscrevem na história dos territórios. Tratase do tempo histórico pensado no plural através da multiplicidade de tempos que se sobrepõem em interações que constantemente remetem para as suas dimensões entre passado e futuro.

Palavras-chave: Antimilitarismo; Esquerda; Portugal.

1 - Antropólogo, investigador no Instituto de História Contemporânea - Universidade Nova de Lisboa. Autor de Pensar a Utopia,Transformar a Realidade (no prelo), 2021, Lisboa, Parfisal. Militante antimilitarista no movimento "Tropa Não" nas décadas de 1980 e 1990. 


\begin{abstract}
The fieldwork, set in the ethnographic present that invariably interrogates the past and its uses to envision the future, often provokes moments of astonishment. In the anthropology that looks at the time that is to come as a kaleidoscope of possibilities, these occasions suggest connections between intersecting worlds, which sometimes diverge and can meet again, always tracing unexpected paths for the projected investigation. In communities that seek in the complexity of the present the simplicity of desired forms of life, which create utopias in the ways of producing, exchanging, educating or deciding among themselves, which transform precariousness into a continued possibility, some of these moments emerged with a bang. In the Pyrenees of the Upper Aragon there are people who live that since the 1970s, who have decisively influenced the anti-militarymovement in Portugal in the late 1980s. This movement contested compulsory military service, the belonging to NATO and the logic of the Cold War that spread missiles across Europe in a tug-of-war that no one could win, involved an urban generation that lived through the 1974 revolution in a time of normalization and the discourse that repudiated the "excesses of the revolution". For the youth that orbited around the Portuguese antimilitary "Movimento Tropa Não", the Spanish example of disobedience to military service, of the conscientious objection that made thousands of arrests in the neighbouring state, mobilizing wide sectors, was both inspiration and complicity, as well as the kick-starter and field of political consciousness. More than thirty years later, these meetings make the memories of those who investigate fundamental material to accompany what one seeks to understand throughout live or in that of social movements that gain other causes. The melancholy that Enzo Traverso (2019) points out as a characteristic for the Left of the $21^{\text {st }}$ century for not having new collective hopes on the horizon, may be being contradicted in the examples of struggles that are inscribed in the history of each specific territory. It is the historical time thought in the plural along the multiplicity of times that overlap in interactions, which constantly refer to its dimensions between past and future.
\end{abstract}

Keyword: Anti-militarism; Left-wing; Portugal.

Nas deambulações de campo onde investiguei caminhos utópicos na construção de realidades concretas, deparei-me com o dever de memória (Nora, 1984), esse impulso que faz de cada pessoa historiadora de si mesma no desejo de resgate de acontecimentos marcantes para grupos que a História não registou, ou pelo menos, não tem confirmada a sua relevância.

Numa viagem de carro entre os Pirinéus aragoneses e navarros, em 2017, apercebo-me da familiaridade dos nomes das localidades por onde passava pela primeira vez. Sem apetência para justificações místicas, a progressão na estrada confirmava o estranhamento só resolvido perante a imagem que me fez revisitar o jovem que fui, nos anos 80 do século passado. Uma imagem de um emblema que usei, começou a pairar insistentemente como que a fazer-me encontrar as emoções 
do reconhecimento perante a memória de uma luta de que fui parte por envolvimento e interesse próprio. Na iminência de cumprir o serviço militar obrigatório, que ameaçava todos os rapazes com 20 anos, envolvi-me no movimento antimilitarista que em Portugal teve a sua expressão mais significativa no movimento "Tropa Não".

Era um emblema ("pin” diz-se agora) com um sorridente instrumento, que celebrava a ação de boicote levada a cabo pelo movimento que contestou a construção de uma barragem. Infraestrutura que prometia a modernidade através da domesticação dos cursos de água da montanha, prometendo desenvolvimento através da paisagem modificada, apesar dos danos colaterais que expulsaram pessoas, condenaram aldeias e sequestraram formas de vida nessa promessa, raramente cumprida, de uma vida melhor.

Danificados os cabos elétricos que forneciam energia à obra, o corta-cabos foi símbolo e senha do movimento, um movimento comunicante com outros, nomeadamente o movimento antilimitarista do Estado espanhol que me fez reencontrar o pin que usei com orgulho.

Nessa viagem, depois de uma curva apertada, vi um vale transformado pela barragem a montante. Foi o momento revelador que explicou as imagens que me assaltavam: estava em Itoiz, o vale que nos anos 90 representou o fim de várias aldeias e viu desalojados os seus habitantes. O pin no casaco de bombazina que usei, celebrava o movimento social que se lhe opôs na temerária ação para atrasar a obra. Cortar os cabos eléctricos foi naquele momento mais do que uma ação simbólica, foi um sinal de engenho, de persistência e imaginação, para quem olhava para o que acontecia no Estado espanhol com atenção e cumplicidade.

Mais tarde, nesse dia, reencontrei os fios desta história. Na aldeia ocupada, hoje com reconhecimento oficial, o movimento contra a barragem marcou profundamente os seus habitantes. Em 1994, catorze anos depois da ocupação inicial, acompanharam de perto o drama dos vizinhos que tiveram de abandonar as suas casas e as suas terras. Sete aldeias deram lugar a um vale inundado. A ação direta que atrasou a obra (celebrada pelo pin que ostentei com orgulho) não foi suficiente para impedir a barragem com todas as suas consequências. Derrotada a luta, formas de vida pulverizadas com a inundação do vale, o passado de várias aldeias e sua população transformou-se na memória dolorosa dessa rutura. Desse dia, lembravam os vizinhos, com os carros que se enchiam de malas, os olhos em lágrimas e o fogo que lavrava solto em algumas casas. Dessa luta, transportam ainda os tempos de prisão que alguns tiveram de cumprir, as multas que ainda estão a pagar, as marcas 
da violência policial que persistem no corpo, sentem ainda a perda e o rancor que nunca conseguiram ultrapassar.

A estrada que me levou à aldeia comunitária circundava a albufeira - inicio de outono, de um ano de seca. Na paisagem lunar, a água estava circunscrita onde a vida parecia exausta e as margens inúteis montes de areia. Nessa desolação, afloravam as ruínas de umas antigas termas, junto a uma nascente de água sulfurosa. Nas construções semi-submersas, as paredes verticais marcavam os espaços das piscinas improvisadas que algumas pessoas continuam a utilizar nos seus banhos terapêuticos. Tal como a nascente continuava a jorrar água quente, a sua humana utilização encontrou formas para continuar. Indiferente ao que ali se construiu, às placas de proibido e de perigo, às ruínas que ficaram e às memórias submersas pela água, o vale aparentemente domesticado reencontrava a persistência que se apropria daquilo que é comum, como a utilização milenar da água.

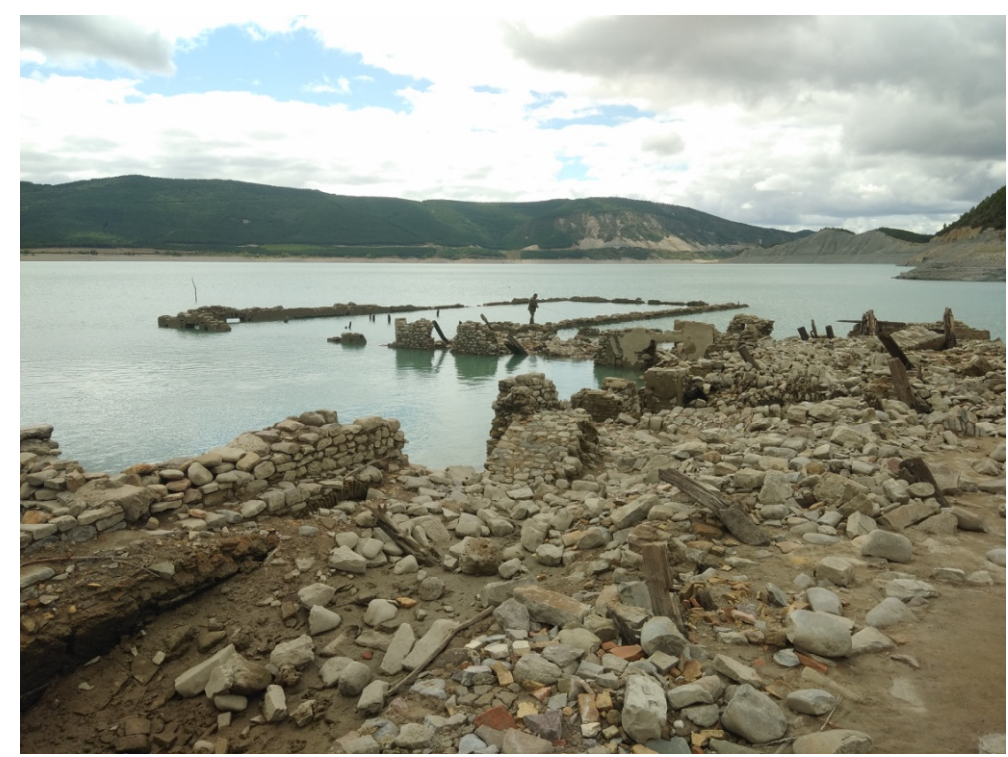

Figura - 1 Ruínas das termas na barragem de Itoiz

O pin na imaginação juvenil dos grandes feitos, ganhava dimensão geográfica e histórica através das memórias dolorosas que me foram relatadas. A antropologia, entre outras coisas igualmente surpreendentes, permite reencontros, por vezes connosco mesmo. Locais de memória revelados sem aviso e que remetem para as articulações do presente com o passado, daquilo que procuramos com aquilo que julgávamos já distante e arrumado noutras gavetas onde procuramos encerrar memórias que julgávamos resolvidas. Mas como nos lembra Pierre Nora (1984), os 
locais de memória são exímios em metamorfoses e em ganhar significados que se entrelaçam sempre em saltos bruscos na temporalidade e nas conexões inesperadas que sugerem ou para as quais remetem insistentemente. O tempo alongado, fraturado, denso, que se pode revisitar, que a antropóloga Paula Godinho (2015) classifica a partir das memórias da resistência à ditadura portuguesa e do processo revolucionário que se seguiu ao golpe de 25 de Abril de 1974 em Portugal, surgia a propósito dessa curva de estrada. Reminiscência do pin que utilizei em jovem, dos encontros com pessoas que afinal se revelaram encontros com aspetos da história pessoal. Tal como peças que surpreendem após se ter desistido do puzle, guardado fora de vista para não lembrar o fracasso nem as nossas limitações. O encaixe das histórias de outros nas narrativas próprias sugere esse processo social em que o espaço é subjetivo e intencional, realidade produzida que articula o passado com o presente na perspetiva de cumprir aspirações e realizar desejos coletivos. Essa viagem de carro pelo vale, agora albufeira de uma barragem, até à aldeia ocupada em 1980 por gente que sem conhecer se tornou próxima, foi o local de memória que me permitiu a revisitação, o momento onde os caminhos de militância que percorri ganharam proximidade e puderem oxigenar o trabalho onde investigava a capacidade utópica e modelos de vida que têm na solidariedade e igualdade as suas premissas fundamentais.

\section{Mili No! A insubmissão para contrariar a guerra.}

Vim a saber nessa tarde, que as pessoas da aldeia que visitei situavam a sua origem militante no movimento antimilitarista que por ali, teve a designação de Insubmissión.

Gente que contestou o serviço militar obrigatório e, algum tempo mais tarde, as normas legais que tentaram conter a vaga de protestos com a lei de objeção de consciência. Insubmissos que usavam a arma da desobediência face à obrigatoriedade de apresentação nos quartéis, ou nos centros de serviço civil. Foram anos em que milhares de pessoas viram as suas convicções sobre a violência organizada e a legitimidade do Estado em se apropriar de tempo de vida, serem pretexto para penas de prisão e duras condenações. Foram anos em que a ideia de insubmissão se alastrava a outros domínios e se transformava em marca de geração, que atravessava fronteiras nacionais e chegava a Portugal, onde despontava também um movimento djuvenil, que olhava para o país vizinho como inspiração para os caminhos de luta contra o mesmo serviço militar obrigatório. 
Em março de 1986, o governo de Felipe Gonzalez realizou um referendo a propósito da permanência espanhola na NATO. O importante movimento antiguerra desses anos que cresceu no Estado espanhol, acompanhando muitos outros países europeus, contestava as políticas da guerra fria, o equilíbrio de terror que assistia à escalada de armamentos entre os dois blocos militares, com a promessa ainda de transferir para o espaço o conflito surdo que opunha os dois mundos separados pelo muro em Berlim. A chantagem do governo socialista, terá funcionado perante o passado recente onde a ditadura franquista estava longe de ser um caso arrumado e o Sim à participação espanhola na NATO ganhou por $53,53 \%$ contra o Não com $39,84 \%$ dos votos. Na Catalunha, País Basco e Canárias o Não saiu vencedor.

$\mathrm{Na}$ semana anterior à realização da consulta, integrei a pequena delegação portuguesa na enorme manifestação que tomou conta das ruas de Madrid e onde a esperança ainda subsistia na possibilidade da vitória que significaria uma enorme conquista para o movimento antiguerra de todo o mundo. Na memória que guardo desses momentos, a multidão que gritava "bases fora", a festa do reconhecimento através da luta partilhada por gerações que olhavam para a postura bélica da aliança militar como a maior ameaça ao seu futuro, recusando o seu aval e a participação do seu país.

Perdido o referendo, o movimento antimilitarista espanhol reconfigurou-se através de organizações como Mili KK ou Katitzak, através ainda de coordenadoras locais que exigiam a abolição do serviço militar obrigatório e da própria instituição militar. A incontornável história do franquismo na sua associação à instituição militar, com as intocáveis figuras dos que transitaram da ditadura para a democracia, sem sobressaltos ou perda de posições nas posições hierárquicas superiores, contribuíam substancialmente para a generalização da desconfiança e terreno fértil para o movimento da Insubmissión.

Como resultado, o início dos anos 1990 viu as prisões encherem-se de gente na recusa de se apresentarem ao serviço militar e também ao serviço civil imposto pela nova lei da objeção de consciência. Milhares de jovens cumpriram penas de um a dois anos pela insubmissão ditada pelas suas convicções política. As prisões voltavam a ter presos políticos (fora do quadro do nacionalismo basco) que se recusavam a servir o Estado de armas na mão, e assim contribuir para um sistema que contestavam ativamente. Carabanchel, a prisão do bairro operário de Madrid que tinha servido para a clausura e tortura dos presos políticos do franquismo, era agora ocupada por insubmissos. Uma ironia que a história do processo de transição para a democracia 
não registou e que os trabalhos de resgate da memória de resistência à ditadura, após a desativação da prisão em 1999, também não.

\section{Tropa Não! A música de uma geração urbana.}

Nesse encontro em 2017, onde os jovens dos anos 90 do século passado ostentávamos já os inevitáveis cabelos brancos, a gaveta das memórias ficou escancarada, deixando entrar luz e ar, que como sabemos, para os assuntos da memória são função higiénica essencial e podem, ao mesmo tempo, representar um perigo fatal.

Desse tempo em que fui militante antimilitarista, militar contrariado e uma das pessoas que asseguravam ligações entre Portugal e Espanha no âmbito deste movimento, guardo as memórias mais fortes e ao mesmo tempo mais distantes.

O Movimento Tropa Não, onde participava, tinha expressão nas cidades de Lisboa e Porto e uma presença crescente em alguns outros centros urbanos através de iniciativas onde o rock era a chave para a expressão e organização do movimento. Era através da música que se tornava visível o absurdo da tropa e do militarismo. Era esse absurdo que justificava a pertença portuguesa na Nato e por isso a um dos lados beligerantes da guerra fria em tempos de afirmação da capacidade nuclear.. Era o militarismo que impunha aos jovens uma sociedade de classes e repleta de uma moral sexista que facilmente desprezávamos. A tropa era o sequestro legal no início da idade adulta e ao simultaneamente a ameaça perante todos os problemas do mundo.

Na música e nas letras do rock de então, os sonhos de todos os tempos, a revolta de uma geração onde a linguagem do protesto ganhou expressão e se fez ouvir ao mesmo tempo que tornava visível cada o absurdo da situação: o serviço militar obrigatório matava e mutilava em acidentes absurdos. Era óbvio que a revolução tinha sido um momento fugaz de que já nada sobrava nos quartéis. 


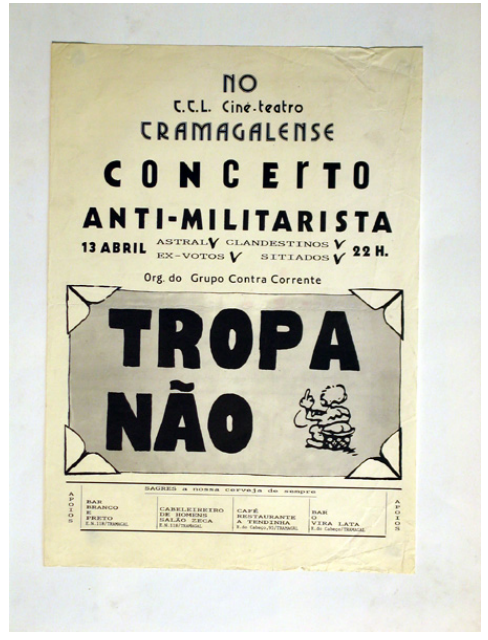

Figura 2 - Cartaz de concerto antimilitarista.

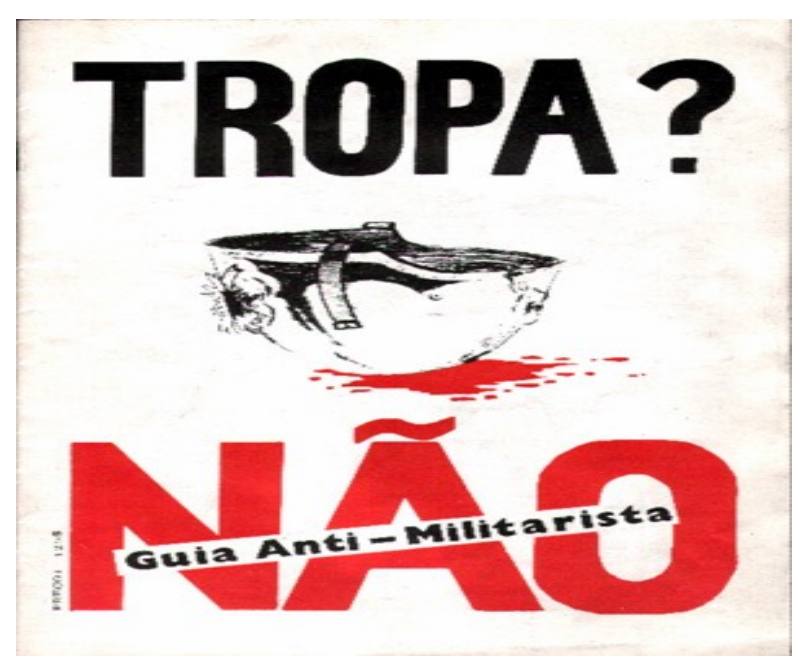

Figura 3 - Capa do primeiro "Guia Anti-Militarista".

Desse momento, por breve que tenha sido, ostentávamos com orgulho a filiação com os SUV - Soldados Unidos Vencerão - organização de base de soldados que no verão de 1975 fez tremer a hierarquia nos quartéis, organizou assembleias e manifestações de gente fardada, combateu a extrema direita bombista, apelou ao internacionalismo proletário e à autoorganização. Os mais velhos de entre nós, transportavam a memória dessa participação nos SUV ${ }^{2}$. Os SUV foram protagonistas desse momento em que o temp acelerou e as possibilidades se abriram escancaradas ao futuro, em que o antimilitarismo foi a enorme vaga que se tinha erguido contra a guerra colonial.

2 - Foi o caso de José Carvalho, operário metalúrgico assassinado em outubro de 1989 por neonazis skinheads durante um concerto antimilitarista de que era organizador, nas Palmeiras, a sede do PSR em Lisboa. O PSR (Partido Socialista Revolucionário) - era a seção portuguesa da Quarta Internacional e foi em 1999 uma das componentes políticas que estiveram na origem do actual Bloco de Esquerda. O partido abria desde 1986 a sua sede e recursos para o Movimento Tropa Não onde participavam muitos dos seus militantes e garantia muitos contactos com os ativistas do Estado espanhol. 


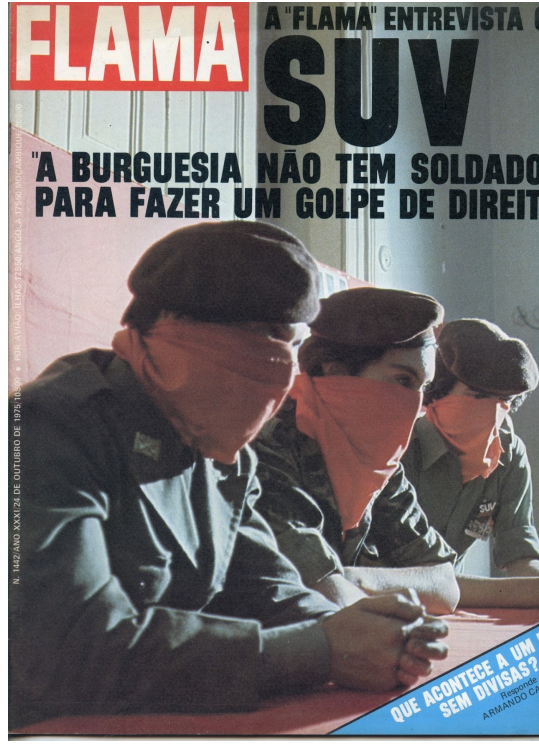

Figura 4 - Capa da revista Flama, outubro 1975.

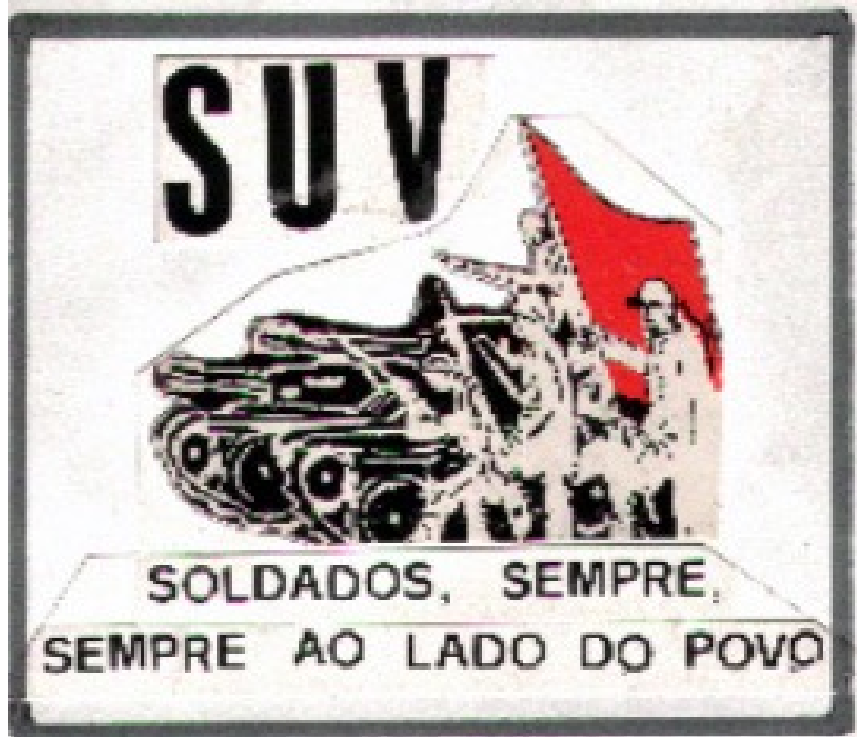

Figura 5 - Autocolante SUV"

Desse momento em que a aliança Povo/MFA ${ }^{3}$ era a consigna generalizada que não escondeu as forças contrárias que emergiam, também para restaurar a disciplina no interior dos quartéis, guardo a hipótese que ali aflorou, sem concretização, mas que na década seguinte, continuou a inspirar o Movimento Tropa Não.

Em 1987, ao mesmo tempo que o presidente angolano, com pompa e circunstância, fazia uma visita de Estado a Portugal, no interior de um quartel de Lisboa eu aprendia que o inimigo voltavam a ser os turras - contração depreciativa para designar os terroristas da guerra colonial que eram afinal os guerrilheiros dos movimentos que tinham libertado as colónias e contribuído decisivamente para o fim da ditadura. $\mathrm{O}$ inimigo que me apontavam nesse momento, fora do quartel, era recebido em festa numa espécie de realidade paralela em que a revolução e a independência dos países africanos parecia não ter acontecido.

Junto com este inimigo imaginário, os espanhóis também eram exemplo didático da ameaça bélica que justificava a instrução militar a que estávamos obrigados. A União Europeia (CEE na altura) já depois da adesão dos dois estados ibéricos, estava bem mais distante que Aljubarrota ${ }^{4}$.

3 - MFA - Movimentos das Forças Armadas, a designação das forças militares que fizeram o 25 de abril de 1974 assegurando o fim da ditadura.

4 - A Batalha de Aljubarrota, em agosto de 1385 entre tropas portuguesas e o exército castelhanoéum dosmomentosaltos da afirmação nacional lusa. As forças portuguesas, apoiadas pela Inglaterra, saem vencedoras da contenda garantindo assim a independência do país e fazendo recuar a expansão de 


\section{Construir futuros com os materiais da memória}

Nessa aldeia basca de Navarra, reinventada nas últimas quatro décadas, alguns protagonistas deste movimento fizeram as suas vidas. Não preciso aqui de descrever em pormenor as suas realizações: desde logo a persistência, mas também a escola para os mais pequenos, a padaria que fornece pão para a cidade, a calcetagem da rua principal, a economia comum porque os recursos são partilhados por todos, os encontros da rede de Eco-aldeias com mais de 500 pessoas, o lixo no ciclo do seu aproveitamento, a rede de águas, o trabalho coletivo, a terra sem propriedade, as assembleias, os consensos e as decisões, as dificuldades e aprendizagens, a integração em múltiplas redes onde a solidariedade se torna concreta e o mundo inteiro o seu lugar.

$\mathrm{Na}$ cartografia que usa a memória, esta aldeia tinha sido o aglomerado de habitações (caserio como dizem por aqueles lados) em torno da propriedade fundiária; com os os seus donos e com as pessoas que os serviam e que para eles trabalhavam a terra. A estrutura social de senhores e servos, de fosso profundo entre classes que se pode ainda reconhecer nas marcas deixadas no espaço agora partilhado. $\mathrm{Na}$ prática dos novos habitantes, só a memória do que já não é, o contrário daquilo que se deseja.

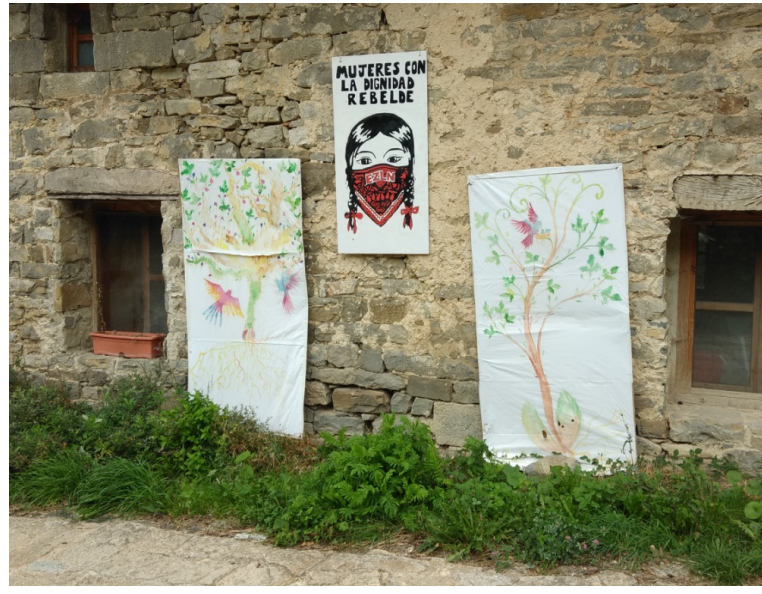

Figura 6 - Exterior da aldeia com cartaz de solidariedade com EZLN (México).

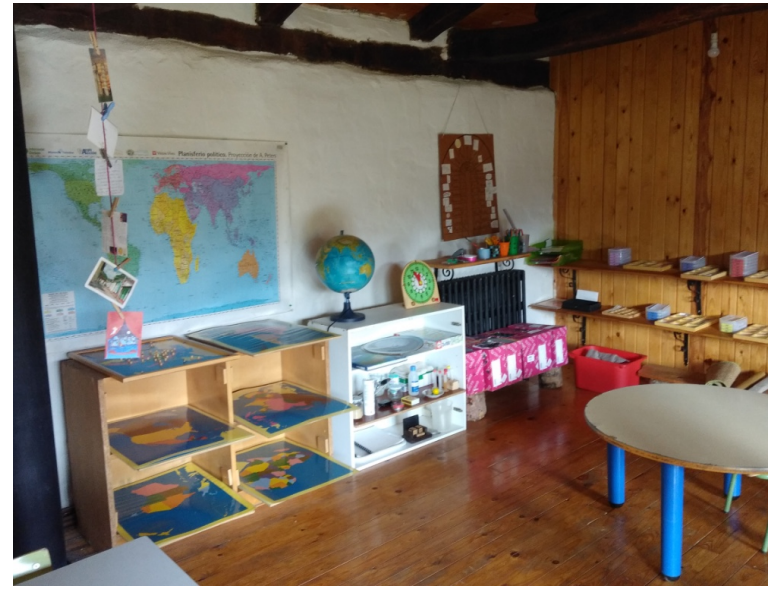

Figura 7 - Sala de aula.

Castela 
Nas camadas de memória a que acrescento uma camada mais, a etnografia regista a convergência ou o acaso, constrói campos de claridade onde havia sombras, insere inesperadamente o investigador na linha do tempo longo do objeto de estudo. Questiona e perturba, entra sem pedir licença nas certezas e objetivos previamente determinados, faz considerar caminhos que não supeitávamos em involuntária autoreflexividade.

Na memória (que não sei se será coletiva), do movimento em que participei, a referência espanhola foi determinante e um poderoso motor para a ação política. Cá e lá, o final do serviço militar obrigatório, uns anos depois. Vitória assinalável, portanto. Mas o militarismo, a Nato, as despesas inúteis em armamento, a manutenção de uma instituição com questionável utilidade social - para mais em contexto de erosão das formas económicas e políticas que decidem a soberania -, tudo isso prosseguiu sem entraves de maior.

Como as derrotas, as vitórias incompletas de movimentos sociais, como este caso, não deixaram de lavrar os terrenos onde vários futuros se disputam em permanência, em processos que retomam memórias a partir do inesperado. A hegemonia aparente e ao mesmo tempo concreta do capitalismo, pode ser surpreendida com o renascer da vida, mesmo a partir das suas ruínas, como que a demonstrar que a história nunca acaba e que a dominação que hoje nos parece de chumbo pode ter afinal pés de barro.

É a pergunta que nos deixa o trabalho da antropóloga AnnaLowenhauptTsing (2015), nas florestas devastadas pela exploração intensiva do Oregon: existirá algo mais além dessa ruína? Poderá a esperança renascer a partir do desconhecido e com ela novas condições para reconstruir a realidade social?

$\mathrm{Na}$ aldeia dos Pirinéus ocupada pelos insubmissos das duas últimas décadas do século XX, um pequeno grupo de pessoas inseridas numa rede global, parece insistentemente dizer-nos que sim. Afinal "o que conta no que foi, é o que seremos", cantava José Mário Branco ${ }^{5}$ na suaSaudação a Antero. Na mesma canção onde exortava, deixando entrever a melodia dos primeiros acordes da Internacional: "de pé memória do futuro, Há sempre luz ao fim do escuro".

5 - José Mario Branco (1942-2019), foi cantautor incontornável na música popular portuguesa Desertor do exército colonial, regressou a Portugal após a revolução de 1974. A sua obra, em grande medida associada às circunstâncias políticas e sociais do país, percorreu gerações e deixou uma marca de génio na cultura portuguesa. Antero de Quental, destinatário da música que lhe é dedicada e aqui referida, foi escritor e poeta do século XIX, socialista influenciado por Proudhon, fundador do primeiro partido operário português. Suicidou-se em 1891. 


\section{Referências Bibliográficas}

CAUSA, M. Martínez i Muntada, R. Historia de la Liga Comunista Revolucionaria. Madrid: La Oveja Roja, 2014.

GARCÍA, Sergio Claudio González . Los Lugares de Memoria en España: una perspectiva espacial de estudio in Godinho Paula, Fonseca, Inês e Baía, João, (Coords.), Resistência ely Memória - Perspectivas Ibero-Americanas [Documento electrónico], Lisboa: IHC-FCSH/UNL, 2014.

GODINHO, Paula . Tempo, memória e resistência in Godinho Paula, Fonseca, Inês e Baía, João, (Coords.), Resistência ely Memória - Perspectivas Ibero-Americanas [Documento electrónico], Lisboa: IHC-FCSH/UNL, 2014.

NORA, Pierre . Les lieux de mémoire. Paris: Gallimard,1984.

TRAVERZO, Enzo . Melancolía de izquierda. Despues de las utopias. Barcelona: Glaxia Gutemberg, 2019.

TSING, Anna Lowenhaupt. The Mushrooms at the End of the World - on the possibility of live in capitalist ruins. Princeton: University Press, 2015.

KOSSELECK, Reinhart . Le Future passé - contribuition à la semantique des temps historiques. Paris: éditions EHES, 2016. 